DOI https://doi.org/10.30525/978-9934-26-113-8-3

\title{
PROSPECTS FOR USE OF ELECTRICAL STIMULATION IN POSTOPERATIVE PHYSICAL REHABILITATION OF PATIENTS WITH UMBILICAL HERNIA
}

\author{
Vasylyk T. P. \\ Director \\ Municipal Non-Commercial Enterprise \\ «City Clinical Hospital No.1 of Ivano-Frankivsk City Council» \\ Vasylyk M. T. \\ Doctor-intern \\ Municipal Non-Commercial Enterprise \\ «City Clinical Hospital No.1 of Ivano-Frankivsk City Council» \\ Ivano-Frankivsk, Ukraine
}

At the current stage of development of herniology, there is an active search for ways to increase the effectiveness of various surgical approaches to the plastic repair of ventral hernias in both experimental $[2,3]$ and clinical areas [6]. Prospect for reconstructive surgery of postoperative ventral hernias, especially large ones, is not in doubt and it is used as a proven method of surgical treatment [1]. At the same time, the researchers also ignore the influence of non-tension plastic methods of repair on neuromuscular synapses (NMS) of muscle fibers and changes in the conductivity of nerve fibers at different levels of their structural organization [4]. Some publications deal with the effect of different modes of electrical stimulation of muscle fibers in ventral hernia [5].

Therefore, the aim of the study was to establish the effectiveness of physical rehabilitation in combination with electrical stimulation on bioelectrical activity of the muscles of the anterior abdominal wall in patients with umbilical hernia.

42 patients with umbilical hernia have been hospitalized in MNCE «IvanoFrankivsk City Clinical Hospital No.1 of Ivano-Frankivsk City Council» from 2016 to 2019. They underwent clinical, laboratory, instrumental examination and surgical treatment. All patients were scheduled for surgery. The age of patients ranged from $40-49$ years (on average $40.2 \pm 8.7$ years).

All examined patients were divided into two clinical groups. The main group included 27 patients who underwent the proposed complex of physical rehabilitation in combination with electrical stimulation with a pulse frequency 
of $10 \mathrm{~Hz}$. The comparison group consisted of 15 patients who didn't have any specific physical rehabilitation measures in postoperative period. All patients of the main group and the comparison group underwent different types of AWR (abdominal wall reconstruction) and Lichtenstein's plastic reconstruction, which involved the implantation of prolene prosthesis (mesh) under the aponeurosis of the rectus abdominis in the umbilical region. The electrical activity of the abdominal muscles was recorded in the preoperative period and 1, 5, 10 days after hernioplasty.

The comparative analysis of data of the anterior abdominal wall EMG showed pronounced denervation-reinnervation electromyographic changes in the preoperative period in different clinical groups of patients with umbilical hernia. Signs of denervation included increased activity during electrode insertion and spontaneous muscle fiber activity. The first was the increase in activity during insertion, followed by an increase in the number and frequency of fibrillation potentials with positive sharp waves.

In the main group, physical rehabilitation was approached individually using an improved program, providing the maximum possible early active mode. This was done using breathing exercises and special passive movements for the upper and lower extremities in combination with electrical stimulation with a pulse rate of $10 \mathrm{~Hz}$ twice a day for 5 minutes for five days.

The effectiveness of postoperative rehabilitation was evaluated by a decrease in flatulence $(43.3 \pm 6.4 \%$ of patients), improved intestinal motor function $(31.7 \pm 6.01 \%)$, increased diaphragmatic motility $(28.3 \pm 5.82 \%)$, reduced dyspnea $(26.7 \pm 5.71 \%)$, reduced tachycardia $(25.0 \pm 5.59 \%)$. Prior to postoperative physical rehabilitation, the heart rate (at rest, in the middle and at the end of the class) in the main group and the comparison group did not differ significantly ( $p>0.05$ ). Thus, in the main group the heart rate was $83.5 \pm 7.2$ beats/min, in the middle of the class $-142.8 \pm 15.6$ beats $/ \mathrm{min}$, at the end of the class $-84.9 \pm 7.0$ beats $/ \mathrm{min}$. The analysis of cardiovascular parameters in patients of the main group allowed us to conclude that classes in the original program of postoperative physical rehabilitation were distributed methodically correctly. At the same time, according to the physiological curve, $30.0 \pm 5.92 \%$ of patients had positive changes, which indicate the adaptation of the cardiorespiratory system to increasing physical activity. Five days after the start of physical rehabilitation complex the electromyographic examination showed that in the muscles of the anterior abdominal wall the activity of the electrode insertion was decreased by $48.3 \%$, compared to the comparison group. During this period, in the main group there were only signs of moderate denervation, the severity of which was weakly correlated $(r=0.30, p>0.05)$ with the severity of pain in the postoperative wound. The histogram of the distribution of action 
potentials by duration had the form of a normal distribution, in which the minimum and maximum duration of individual action potentials did not exceed $\pm 20.2 \%$ (critical value $\pm 30.0 \%$ ) of the normative value of the average duration of the action potential, which is $14.5 \%(\mathrm{p}<0.05)$ less than in the comparison group. In general, according to electromyograms of the muscles of the anterior abdominal wall, in the main group there was a rapid normalization of the function of rectus and oblique muscles of the abdomen, while patients in the comparison group had denervation-reinnervation processes of stage 2 , which indicates the development of myopathy.

Thus, the analysis of cardiovascular performance indicates the safety and effectiveness of a proposed program of postoperative physical rehabilitation in combination with electrical stimulation with a pulse rate of $10 \mathrm{~Hz}$ in patients with umbilical hernia. This allowed to complete sick leave after hernioplasty much earlier (on average from 36.6 to 27.4 days).

\section{References:}

1. Chernykh A. V., Zakurdaev E. I., Cherednikov E. F., Vitchinkin V. New data on the variant anatomy of the arcuate line by J. Douglas of the aponeurotic sheath of the rectus abdominis muscles and their significance in herniology. Vestnik eksperimentalnoy i klinicheskoy khirurgii. 2018. Vol. 11, № 2. P. 93-96.

2. Chernykh A. V., Popova M. P. Features of topography of the intercostal nerves in the region of the anterior abdominal wall, depending on the body type. Zhurnal anatomii i gistopatologii. 2019. Vol. 8, № 2. P. 77-81.

3. Faylona J. M. Evolution of ventral hernia repair. Asian Journal of Endoscopic Surgery. 2017. Vol. 10, №3. P. 252-258.

4. Nastuk W. L. The Motor Endplate. Archives of Neurology. 2012. Vol. 11, №6. P. 684-685.

5. Samosyuk I. Z., Chukhraev N. V., Samosyuk N. I., Chukhraeva E. N. Electrotherapy and electropuncture in medical rehabilitation, physiotherapy and balneology. Kiev. 2012. 291 P.

6. Tarasenko S. V., Zaitsev O. V., Kopeikin A. A., Akhmedov Sh. I., Rakhmaev T. S. Method of strengthening the posterior wall of the inguinal canal with a straight inguinal hernia by plastic repair of the transverse fascia of the endo-loops. Vestnik eksperimentalnoy $i$ klinicheskoy khirurgii. 2015. Vol. 8, №3. P. 310-313. 